\title{
Rate-dependent force, intracellular calcium, and action potential voltage alternans are modulated by sarcomere length and heart failure induced-remodeling of thin filament regulation in human heart failure: A myocyte modeling study
}

\author{
Melanie A. Zile ${ }^{\mathrm{a}}$ and Natalia A. Trayanova ${ }^{\mathrm{b} *}$ \\ ${ }^{a}$ Institute for Computational Medicine and Department of Biomedical Engineering at Johns \\ Hopkins University, 3400N Charles St, 316 Hackerman Hall, Baltimore, MD 21218, USA. \\ Electronic address: mzile@jhu.edu \\ ${ }^{\mathrm{b}}$ Institute for Computational Medicine and Department of Biomedical Engineering at Johns \\ Hopkins University, 3400N Charles St, 316 Hackerman Hall, Baltimore, MD 21218, USA. \\ Electronic address: ntrayan1@jhu.edu \\ * Corresponding Author
}
Abbreviations:
APV-ALT $=$ action potential voltage alternans
APV-ALTM = action potential voltage alternans magnitude
$[\mathrm{Ca}]_{\mathrm{i}}=$ free intracellular calcium concentration
$\mathrm{CA}-\mathrm{ALT}=[\mathrm{Ca}]_{\mathrm{i}}$ alternans
$\mathrm{CA}-\mathrm{ALTM}=[\mathrm{Ca}]_{\mathrm{i}}$ alternans magnitude
$\mathrm{CL}=$ cycle length
$[\mathrm{Ca}]_{\text {Troponin }}=$ total calcium bound to Troponin $\mathrm{C}$
FORCE-ALT $=$ active force alternans
FORCE-ALTM = active force alternans magnitude
$\mathrm{RU}=$ regulatory unit
$\mathrm{SL}=$ sarcomere length
$\mathrm{XB}=$ crossbridge 


\section{Keywords}

force alternans; action potential alternans; pressure alternans; heart failure; computer modeling 


\section{Introduction}

Ventricular arrhythmias are the most common cause of sudden cardiac death, resulting in $>$ 300,000 US deaths annually (Lloyd-Jones et al., 2009). The standard procedure for preventing sudden cardiac death is to implant a cardioverter defibrillator (ICD), which delivers a strong electric shock to terminate arrhythmias. Since current methods for identifying patients who require ICDs have only been partially successful (Bardy et al., 2005), there is a need for noninvasive predictors with high sensitivity and specificity. Indeed, robust methods for stratifying the risk of lethal cardiac arrhythmias would decrease morbidity and mortality in patients with cardiovascular disease and reduce health care costs (Goldberger et al., 2011). Approaches for stratifying risk of cardiac arrhythmias involve testing for abnormalities in the ECG, then using the results to identify patients who would benefit from ICD therapy. ECG-based risk stratification methods scan for abnormalities in ventricular depolarization (late potentials (Kuchar et al., 1987), fractionated QRS complexes (Das et al., 2006)) and repolarization (Twave alternans (Rosenbaum et al., 1994), and QT variability, dispersion, and instability (Berger et al., 1997; Chen et al., 2011; Chen et al., 2013; Chen and Trayanova, 2012; Couderc et al., 2007)). However, the mechanisms underlying these ECG indices, and their relationship to lethal cardiac arrhythmias, are not fully understood. This lack of knowledge likely explains why results of clinical trials to correlate surface EGG indices to lethal cardiac arrhythmias are often contradictory (Goldberger et al., 2011).

Of the above ECG indices, T-wave alternans have received possibly the most attention. Research has reported a strong correlation between increased arrhythmia risk and the presence of T-wave alternans (Narayan, 2006; Qu et al., 2010), defined as the beat-to-beat alternation of the timing or shape of the repolarization wave of the ECG. In the clinical setting, testing for Microvolt T-wave Alternans (MTWA) has been found to be a risk marker for lethal ventricular arrhythmias and sudden cardiac death (Cutler and Rosenbaum, 2009), to have high negative predictive power (Narayan, 2006) and to be particularly promising in dichotomizing patients that would and would not benefit from ICD therapy (Bloomfield et al., 2006; Hohnloser et al., 2009). However, the mechanistic basis of MTWA preceding lethal ventricular arrhythmias has long been under debate. Until the last decade, it was believed that a steep action potential duration (APD) restitution $(>1$ ) at rapid heart rates (Weiss et al., 2006) produces alternans in APD that underlie T-wave alternans and the genesis of fibrillation (Pastore et al., 1999). However, MTWA is most successful in stratifying risk in patients at near-resting heart rates $<110 \mathrm{bpm}$, where APD restitution is flat (Narayan et al., 2007). Computational models of the LV wall in combination with clinical data revealed that abnormal handing of intracellular calcium underlies alternans in action potential voltage (APV-ALT), defined as the oscillation of the plateau voltage of the action potential, which results in MTWA at moderate heart rates, i.e. $<110 \mathrm{bpm}$ (Bayer et al., 2010; Narayan et al., 2008). Thus APV-ALT is the cell-level driver of MTWA at these rates under the conditions of heart failure.

Alternatively, noninvasively measured pressure alternans, defined as the beat-to-beat oscillation of the amplitude of systolic pressure, has been found to be a predictor of worsening heart failure and increased cardiac mortality (Hirashiki et al., 2010; Hirashiki et al., 2006; Ito et al., 2012; Kashimura et al., 2014; Kim et al., 2014; Selvaraj et al., 2011). Pressure alternans also occurs simultaneously with MTWA in patients at near resting heart rates, thus indicating that pressure alternans, which have higher signal-to-noise ratio (Selvaraj et al., 2011), may be a better 
predictor of the propensity for ventricular arrhythmias and sudden cardiac death, however the mechanisms remain unknown.

At the cellular level, pressure alternans arise from force alternans (FORCE-ALT), defined as the beat-to-beat oscillations in the strength of active force production in cardiac muscle. APV-ALT at heart rates $<110 \mathrm{bpm}$ has been found to be driven by beat-to-beat fluctuations in the amplitude of the intracellular calcium concentration (CA-ALT) (Bayer et al., 2010; Narayan et al., 2008). CA-ALT has also been shown to underlie force alternans (FORCEALT), in animal experiments with cardiac muscle preparations (Kihara and Morgan, 1991; Kotsanas et al., 1996; Lab and Lee, 1990; Orchard et al., 1991) and perfused hearts (Brooks et al., 1994; Lee et al., 1988), but only at fast pacing rates. Clearly, to date, no studies have investigated FORCE-ALT in human myocytes at rates $<110 \mathrm{bpm}$, and although calcium dysregulation is a likely candidate, the exact mechanistic link between APV-ALT and FORCEALT in the failing human myocyte at the clinically important near-resting heart rates remains unknown. Therefore, our goal was to investigate the mechanisms linking FORCE-ALT to APVALT in the human failing myocyte, with emphasis on those acting at the clinically-relevant pacing rates of $<110 \mathrm{bpm}$, and to uncover how the link between FORCE-ALT and APV-ALT is affected by various physiological conditions such as sarcomere length and heart failure inducedremodeling of mechanical parameters.

\section{Methods}

\subsection{Human Electromechanical Myocyte Model}

To uncover the mechanism linking FORCE-ALT to APV-ALT, a mechanistically-based human electromechanical myocyte model was used. The electromechanical model combined the human endocardial ventricular membrane kinetics model by ten Tusscher et al (ten Tusscher and Panfilov, 2006) and the myofilament dynamics model by Rice et al (Rice et al., 2008). The 2006 ten Tusscher et al formulation was used because it incorporated an extensive description of intracellular calcium handling, which was found to be critical in the development of APV-ALT in previous studies of human heart failure (Bayer et al., 2010; Narayan et al., 2008). The Rice $e t$ al model, which describes the activation of the thin filament by intracellular calcium binding to Troponin $\mathrm{C}$ as well as thin filament binding to thick filament crossbridges (XBs) using a 5 state Markov model, was chosen because it was computationally efficient while incorporating important biophysical detail and cooperativity mechanisms. Since the Rice et al myofilament model was developed based on rabbit data we adjusted it to match human force data. This was done by modifying XB cycling and calcium-based thin filament activation parameters following the approach in de Oliveira et al (de Oliveira et al., 2013). To account for the differences between the ionic model used by de Oliveira et al (the 2004 formulation of the ten Tusscher et al model (ten Tusscher et al., 2004)) and by us (ten Tusscher and Panfilov, 2006), additional modifications to calcium-based thin filament activation were made. Specifically, we decreased thin filament activation by reducing $\mathrm{k}_{\mathrm{on}}$, a parameter regulating the binding affinity of $\mathrm{Ca}$ to high and low regulatory sites on Troponin C, to $95 \%$ of the baseline value used in Rice et al, in order to increase the time to peak force value so that it fell in the physiological range of human values (Mulieri et al., 1992; Pieske et al., 1996).

The ionic and myofilament models were strongly coupled by incorporating myofilament feedback on calcium dynamics (Figure 1); this was done by incorporating a dynamic term for troponin buffering of intracellular calcium $\left([\mathrm{Ca}]_{\text {Troponin }}\right)$ using the approach in Rice et al. Strongly 
coupling the models with a dynamic representation of $[\mathrm{Ca}]_{\text {Troponin }}$ was important and necessary, because it has been shown to be crucial for accurately reproducing contractile experiment data in myocyte simulations (Ji et al., 2015). This $[\mathrm{Ca}]_{\text {Troponin }}$ term represents the amount of calcium bound to troponin and incorporates the cooperativity of calcium-troponin binding due to strongly bound nearby XBs. However, in the 2006 ten Tusscher and Panfilov model, troponin buffering of calcium is combined with calmodulin buffering of calcium and is represented using a steady state approximation. Therefore, to incorporate feedback from the myofilament model to the ionic model, we separated the combined buffering term in ten Tusscher and Panfilov into two terms. The $[\mathrm{Ca}]_{\text {Troponin }}$ term from Rice et al, calculated using ordinary differential equations, was used for troponin buffering of calcium, and a steady state approximation was used for calmodulin buffering of calcium ([Ca $\left.]_{\text {Calmodulin }}\right)$ using the same approach as de Oliveira et al. The following equation from de Oliveira et al was used to update the intracellular calcium concentration in the ionic model, using the $[\mathrm{Ca}]_{\text {Troponin }}$ term calculated by the myofilament model, at each time step:

$$
[\mathrm{Ca}]_{\text {Total }}=[\mathrm{Ca}]_{i}+[\mathrm{Ca}]_{\text {Calmodulin }}+[\mathrm{Ca}]_{\text {Troponin }}
$$

where $[\mathrm{Ca}]_{\text {Total }}$ is the total calcium in the cytoplasm, $[\mathrm{Ca}]_{\mathrm{i}}$ is the free calcium in the cytoplasm, $[\mathrm{Ca}]_{\text {Calmodulin }}$ is the total calcium buffered by calmodulin in the cytoplasm, and $[\mathrm{Ca}]_{\text {Troponin }}$ is the total calcium bound to Troponin $\mathrm{C}$.

A weakly coupled version of the model (with no feedback) was created by removing the $[\mathrm{Ca}]_{\text {Troponin }}$ term from Equation 1. Its sole purpose was to aid in examining how myofilament feedback affected the development of alternans.

The model did not incorporate stretch-activated channels since there is no experimental evidence that heart-failure induced APV-ALT at low heart rates would be affected by a potential opening of the channel.

\subsection{Incorporating Heart Failure Remodeling}

We simulated human heart failure in our electromechanical model by incorporating electrical and mechanical remodeling. Electrical remodeling was represented by abnormal calcium handing. Specifically, we reduced the sarcoplasmic reticulum calcium uptake current $\left(\mathrm{I}_{\mathrm{up}}\right)$ to $27 \%$ of its baseline value in the ten Tusscher et al model (Table 1), similar to Narayan et al (Narayan et al., 2008) and Bayer et al (Bayer et al., 2010), to represent reduced SERCA2a expression (Hasenfuss et al., 1994) and increased dephosphorylated phospholamban (Schmidt et al., 1999) observed in human heart failure. This specific feature of heart failure remodeling was incorporated because it has been shown to be crucial to the development of APV-ALT in previous studies of human heart failure (Bayer et al., 2010; Narayan et al., 2008).

Mechanical remodeling was incorporated to simulate altered thin filament activation and $\mathrm{XB}$ cycling rates found in human heart failure. Changes in thin filament activation have been linked to altered phosphorylation of cardiac Troponin I (cTnI) (Messer et al., 2007), which has been shown to be decreased by up to $87 \%$ (Messer et al., 2007; Zaremba et al., 2007). Alterations in XB cycling rates have been linked to changes in phosphorylation of myosin light chain 2 (MLC-2) (Levine et al., 1996; Moss and Fitzsimons, 2006; Olsson et al., 2004; Patel et al., 1998) and cardiac myosin-binding protein C (cMyBP-C) (Coulton and Stelzer, 2012; Flashman et al., 2004). Studies have found that phosphorylation of the two isoforms of MLC-2 is unchanged (van der Velden et al., 2003a) or reduced by 34\%-69\% (van Der Velden et al., 2001; van der Velden et al., 2003a; van der Velden et al., 2003b; Zaremba et al., 2007). Additionally, cMyBP-C has 

Furthermore, myocardial $\mathrm{Ca}^{2+}$ sensitivity, which incorporates the combination of the effects of thin filament activation and XB cycling rates on force production, has been shown to be altered in human heart failure. In studies, myocardial $\mathrm{Ca}^{2+}$ sensitivity has been found to increase by 2$6 \%$ in human heart failure (van der Velden et al., 2000; van der Velden et al., 2006; Wolff et al., 1996) and by 1-2\% in animal models of heart failure (de Waard et al., 2007; Lamberts et al., 2007; Wolff et al., 1995), not change in human heart failure (Ambardekar et al., 2011), and decrease by 2-3\% in animal models of heart failure (Belin et al., 2007; Belin et al., 2006).

Despite the uncertainty regarding the exact amount by which the mechanical properties outlined above are altered in heart failure, these studies indicate that mechanical parameters involved in thin filament activation and XB cycling are important components of the disease manifestation and therefore might contribute to the development of FORCE-ALT. To elucidate if and how changes to mechanical parameters in human heart failure promote or modulate FORCEALT, we incorporated mechanical remodeling into the Rice et al myofilament model. Specifically, we altered thin filament activation, embodied in the Rice et al model by these 6 parameters: $\operatorname{perm}_{50}, \mathrm{k}_{\mathrm{offL}}, \mathrm{k}_{\mathrm{offH}}, \mathrm{k}_{\mathrm{on}}, \mathrm{k}_{\mathrm{n} \_\mathrm{p}}$, and $\mathrm{k}_{\mathrm{p} \_n}$. $\mathrm{k}_{\mathrm{npT}}$ and $\mathrm{k}_{\mathrm{pnT}}$ are nonlinear transition rates that are functions of these 6 parameters and represent calcium based activation of the thin filament, which is shown in Figure 1 as the transition of the thin filament from the $\mathrm{N}_{\mathrm{XB}}$ state (XB formation is inhibited) to the $\mathrm{P}_{\mathrm{XB}}$ state (weakly bound $\mathrm{XB}$ formation is possible). Specifically, perm $_{50}$ is the half activation constant for shift of a thin filament regulatory unit (RU) from $\mathrm{N}_{\mathrm{XB}}$ to $\mathrm{P}_{\mathrm{XB}}, \mathrm{k}_{\mathrm{OffH}}\left(\mathrm{k}_{\mathrm{offL}}\right)$ is the rate constant for $\mathrm{Ca}^{2+}$ unbinding from the high (low) affinity binding site of Troponin $\mathrm{C}$, and $\mathrm{k}_{\mathrm{on}}$ is rate constant for $\mathrm{Ca}^{2+}$ binding to Troponin $\mathrm{C}$. $\mathrm{k}_{\mathrm{n} \_\mathrm{p}}$ and $\mathrm{k}_{\mathrm{p} \_\mathrm{n}}$ are constant scaling factors of the $\mathrm{k}_{\mathrm{npT}}$ and $\mathrm{k}_{\mathrm{pnT}}$ transition rates. We also altered $\mathrm{XB}$ cycling rates, expressed by these Rice et al parameters: $\mathrm{f}_{\mathrm{app}}, \mathrm{g}_{\mathrm{app}}, \mathrm{h}_{\mathrm{f}}, \mathrm{h}_{\mathrm{b}}$, and $\mathrm{g}_{\mathrm{xb}}$. The rates fapp and gapp regulate the transition of the thin filament from the $\mathrm{P}_{\mathrm{XB}}$ state to the strongly bound $\mathrm{XB}$ state where the myosin head has not yet rotated and induced strain in the neck region $\left(\mathrm{XB}_{\text {PreR }}\right) . \mathrm{h}_{\mathrm{f}}$ and $\mathrm{h}_{\mathrm{b}}$ are transition rates between the $\mathrm{XB}_{\mathrm{PreR}}$ and $\mathrm{XB}_{\text {PostR }}$ state (thin filament is strongly bound to a $\mathrm{XB}$ which has a rotated myosin head and has induced distortion). $\mathrm{g}_{\mathrm{xb}}$ represents the ATP consuming transition rate from $\mathrm{XB}_{\text {PostR }}$ to $\mathrm{P}_{\mathrm{XB}}$. Due to the uncertainty in the literature regarding the exact amount that these parameters change in heart failure, as described above, we explored heart failure-induced remodeling of these 11 myofilament parameters within the range of $80 \%$ to $120 \%$ of their baseline values (Table 1).

\subsection{Alternans Protocol}

Clinical studies in patients with human heart failure have shown that APV-ALT arises at moderate pacing rates (Narayan et al., 2008); APV-ALT has also been induced, at these rates, in computational electrophysiological models of human myocytes and LV wedges with abnormal calcium handing by pacing the models with a dynamic pacing protocol (Bayer et al., 2010). To induce APV-ALT in our electromechanical model of the myocyte, we used a pacing protocol similar to that in Bayer et al. (Bayer et al., 2010). We first paced the myocyte at near resting pacing rates $(850 \mathrm{~ms} ; 71 \mathrm{bpm})$ until steady state was reached. Then, a dynamic pacing protocol was executed with pacing beginning at a cycle length (CL) of $650 \mathrm{~ms}$ (92 bpm) and decreasing by 50 ms every 100 beats, until loss of 1:1 capture occurred.

Since our myocyte model is a strongly coupled electromechanical model, the procedure used to induce APV-ALT was also expected to result in the generation of FORCE-ALT. We 

The pacing protocol also allowed us to probe the sensitivity of FORCE-ALT to CL.

To elucidate if altered thin filament activation and XB cycling rates found in human heart failure exacerbated or alleviated FORCE-ALT, we examined how each remodeled parameter described above individually affected FORCE-ALT; 11 sets of simulations were thus run using the dynamic pacing protocol, each including the electrical remodeling and the remodeling of one of the myofilament parameters. To uncover the effect of disease severity for each remodeled myofilament parameter, each set of simulations consisted of 41 unique simulations in which the chosen mechanical parameter was assigned a value in the range of $80 \%$ to $120 \%$ of its baseline value in Rice et al (incremented by $1 \%$ ). To discover if FORCE-ALT can be induced by mechanical remodeling and dynamic pacing alone, the 451 simulations just described were executed again but without the inclusion of electrical remodeling.

Finally, since active force generation is known to be modulated by sarcomere length (SL) (Gordon et al., 1966), we wanted to uncover if FORCE-ALT was also sensitive to SL. To do this, the aforementioned 451 simulations (with the electrical remodeling) were each run 16 times, during which we held SL constant at a different value for each simulation. SL values ranged from $1.65 \mu \mathrm{m}$ to $2.4 \mu \mathrm{m}$, in increments of $0.05 \mu \mathrm{m}$. This range of SL values was chosen because it is in the operating range for cardiac myocytes (Trayanova and Rice, 2011).

\subsection{Alternans Analysis}

The magnitudes of alternans in active force, intracellular calcium concentration $\left([\mathrm{Ca}]_{\mathrm{i}}\right)$, and transmembrane voltage $\left(\mathrm{V}_{\mathrm{m}}\right)$ were each calculated using the following formula commonly used in the quantification of alternans (Kockskamper and Blatter, 2002; Shkryl et al., 2012; Xie et al., 2013):

$$
\text { ALTM }=1-\frac{\text { Small Amplitude }}{\text { Large Amplitude }}
$$

where Small Amplitude is the peak value minus the minimum value during the small beat and Large Amplitude is the peak value minus the minimum value during the large beat. Alternans magnitude was calculated for each pair of beats during the final 64 beats of each CL, following the approach in Bayer et al (Bayer et al., 2010) and the largest alternans magnitude per CL for each simulation was recorded. APV-ALT was calculated, as described above, during the period from the start of Phase II until the end of Phase III of the action potential. Alternans occurred if $\mathrm{ALT}>0$.

\section{Results}

\subsection{Abnormal Intracellular Calcium Handling Results in Force Alternans}

Incorporating heart failure electrical remodeling in our strongly coupled cellular electromechanical model (as described in Methods) resulted, as expected, in intracellular calcium alternans (CA-ALT) that caused action potential voltage alternans (APV-ALT), similar to those shown previously (Bayer et al., 2010; Narayan et al., 2008). An example of CA-ALT as a function of time and as superimposed beats is shown in Figure 2, panels A and E respectively, for pacing at a CL of $650 \mathrm{~ms}(92 \mathrm{bpm})$ and for a SL of $2.1 \mu \mathrm{m}$ (a typical length during the normal cardiac cycle). The superimposed beats emphasize the presence of CA-ALT and the 

transient) beats. The corresponding APV-ALT is shown in Figure 2, panels B and F. CA-ALT also induced alternans in active force (FORCE-ALT), shown as a function of time (Figure 2C) and as overlaid beats (Figure $2 \mathrm{H}$ ).

Due to myofilament feedback in our strongly coupled model (Figure 2, panels C and G), CA-ALT and APV-ALT differed from those obtained by Bayer et al and Narayan et al (Bayer et al., 2010; Narayan et al., 2008). We used the weakly coupled version of the model to explore the effects of myofilament feedback on CA-ALT, APV-ALT, and FORCE-ALT (compare rows 2 and 3 of Figure 2). The magnitudes of $[\mathrm{Ca}]_{\mathrm{i}}$ and CA-ALT (CA-ALTM) were both smaller in the strongly coupled model as compared to those in the weakly coupled ([Ca $]_{i}: 0.44 \mu \mathrm{M}$ vs $0.50 \mu \mathrm{M}$ for odd beat, $0.51 \mu \mathrm{M}$ vs $0.68 \mu \mathrm{M}$ for even beat; CA-ALTM: $21 \%$ vs $35 \%$ ). Since Troponin C binds free intracellular calcium and thus removes those calcium ions from the pool of free calcium available in the cytoplasm $\left([\mathrm{Ca}]_{\mathrm{i}}\right)$, the feedback via the $[\mathrm{Ca}]_{\text {Troponin }}$ term (Equation 1) in the strongly coupled model resulted in a smaller magnitude of $[\mathrm{Ca}]_{\mathrm{i}}$. Smaller CA-ALTM was due to the fact that Troponin $\mathrm{C}$ buffers more $[\mathrm{Ca}]_{\mathrm{i}}$ when $[\mathrm{Ca}]_{\mathrm{i}}$ transient is large (even beat) than when it is small (odd beat), thus reducing the peak magnitude of $[\mathrm{Ca}]_{\mathrm{i}}$ during the even beat relative to that of the odd and consequently decreasing CA-ALTM, as calculated according to Equation 2. The magnitude of APV-ALT (APV-ALTM) was also smaller in the strongly coupled model (46\% vs. $68 \%$ with no feedback) due to diminished CA-ALTM. The magnitude of $[\mathrm{Ca}]_{\text {Troponin }}$ was smaller in the strongly vs weakly coupled model ([Ca $]_{\text {Troponin: }} 8.73 \mu \mathrm{M}$ vs $13.19 \mu \mathrm{M}$ for odd beat, $14.86 \mu \mathrm{M}$ vs $24.17 \mu \mathrm{M}$ for even beat) due to diminished $[\mathrm{Ca}]_{\mathrm{i}}$. The strong coupling also resulted in a smaller magnitude of the active force due to the decreased $[\mathrm{Ca}]_{\mathrm{i}}$ transient $(0.18 \mathrm{vs}$ 0.36 normalized force for odd beat, 0.46 vs 0.79 for even beat). However, the magnitude of FORCE-ALT (FORCE-ALTM) was $5 \%$ greater in the case of myofilament feedback than without (60\% vs. $55 \%)$, despite the smaller CA-ALTM in the former case. This was due to a smaller amount of calcium bound to Troponin $\mathrm{C}$ during both the odd and even beats, resulting from the reduced $[\mathrm{Ca}]_{\mathrm{i}}$ in this case. Since calcium binding to Troponin $\mathrm{C}$ activates the thin filament, less thin filament regulatory units (RUs) transitioned from the non-permissive $\left(\mathrm{N}_{\mathrm{XB}}\right.$; $\mathrm{XB}$ formation is inhibited) to the permissive ( $\mathrm{P}_{\mathrm{XB}}$; weakly-bound $\mathrm{XBs}$ formation possible) state, (Figure 1) resulting in less RUs transitioning from $\mathrm{P}_{\mathrm{XB}}$ to the states with strongly-bound $\mathrm{XBs}$ $\left(\mathrm{XB}_{\text {PreR }}\right.$ and $\left.\mathrm{XB}_{\text {PostR }}\right)$. Since active force is generated by the rotation of the thick filament, fewer RUs in the pre-rotated $\left(\mathrm{XB}_{\mathrm{PreR}}\right)$ state caused less RUs to transition from it to the post-rotated $\left(\mathrm{XB}_{\text {PostR }}\right)$ state, producing less active force. However, since the presence of strongly bound XBs is known to enhance the binding affinity of Troponin $C$ to calcium on nearby thin filament RUs and since Rice et al (Rice et al., 2008) incorporated this nonlinear cooperativity mechanism, the relatively smaller amount of strongly bound XBs during the odd (smaller $[\mathrm{Ca}]_{\mathrm{i}}$ ) beat resulted in greater reduction of active force generation relative to the even (larger $[\mathrm{Ca}]_{\mathrm{i}}$ ) beat. This resulted in enhanced FORCE-ALTM in the strongly coupled model as calculated according to Equation 2.

\subsection{Sensitivity of Alternans to Pacing Rate}

Simulations with our strongly coupled electromechanical myocyte model revealed that FORCE-ALTM has a non-monotonic dependence on CL (Figure 3A, solid line), with a local minimum at $\mathrm{CL}=400 \mathrm{~ms}$. CA-ALTM monotonically increased with increased pacing rate, while APV-ALTM remained relatively small at slower pacing rates and increased at faster pacing rates (Figure 3B-C, solid line). No alternans occurred for pacing CLs>650 ms. An important 
observation here is that for all clinically relevant pacing rates (as discussed in the Introduction, $<110$ bpm; CL $>=550 \mathrm{~ms}$ ), CA-ALTM, ranging 21\%-31\%, induced smaller APV-ALTM (ranging 46-48\%) but larger FORCE-ALTM (ranging 51-61\%), consistent with the results presented in Figure 2. However, at faster pacing rates (CL $<500 \mathrm{~ms}$ ), larger CA-ALTM induced smaller FORCE-ALTM. This was due to elevated $[\mathrm{Ca}]_{i}$, which occurred due to a buildup of diastolic intracellular calcium as a result of insufficient time between beats for the SERCA pump and the $\mathrm{Na} / \mathrm{Ca}^{2+}$ exchanger to restore $[\mathrm{Ca}]_{\mathrm{i}}$ to normal. During the large (even) beat, this abnormally large $[\mathrm{Ca}]_{\mathrm{i}}$ transient saturated Troponin $\mathrm{C}$ prior to reaching its peak magnitude, preventing additional free calcium from binding to Troponin $\mathrm{C}$ and thus preventing an increase in thin filament activation. This prevented further thin filament RUs from transitioning to the $\mathrm{P}_{\mathrm{XB}}, \mathrm{XB}_{\text {PreR }}$ and $\mathrm{XB}_{\text {PostR }}$ states from the $\mathrm{N}_{\mathrm{XB}}$ state (Figure 1). Since no additional rotation of the thick filament occurred, no added active force was generated during the even beat, despite additional free calcium becoming available as the $[\mathrm{Ca}]_{\mathrm{i}}$ transient increased from the value at which Troponin $\mathrm{C}$ saturated to its peak magnitude. This resulted in diminished FORCE-ALTM at faster pacing rates, according to Equation 2.

Eliminating myofilament feedback reduced FORCE-ALTM at all CLs on average by $11 \%$, flattened the CA-ALTM dependence, and increased APV-ALTM (Figure 3A-C, dashed line), rendering the latter similar to the dependence documented by Bayer et al and Narayan et al (Bayer et al., 2010; Narayan et al., 2008). CA-ALTM was smaller for the strongly verses the weakly coupled model at slower pacing rates (CL>450 ms), consistent with the results presented in Section 3.1 for $\mathrm{CL}=650 \mathrm{~ms}$ (Figure 2). However, CA-ALTM became larger than that for the weakly coupled model at faster pacing rates (CL<400 ms) due to diminished myofilament feedback during the even but not the odd beat. As CL decreased, $[\mathrm{Ca}]_{\mathrm{i}}$, was elevated and saturated Troponin $\mathrm{C}$ during the even beat, preventing both additional free calcium from binding to Troponin $\mathrm{C}$, and additional thin filament RUs from transitioning from the $\mathrm{N}_{\mathrm{XB}}$ to the $\mathrm{P}_{\mathrm{XB}}$ and strongly-bound XB states, as discussed in the preceding paragraph. Since $[\mathrm{Ca}]_{\text {Troponin }}$ is a function of the amount of calcium bound to Troponin $\mathrm{C}$ and of the number of RUs in the strongly-bound XB states, myofilament feedback was diminished during the even beat more than the odd, thus reducing the magnitude of $[\mathrm{Ca}]_{\mathrm{i}}$ more during the odd beat. This resulted in larger CA-ALTM for the strongly coupled model at faster rates.

\subsection{Dependence of Force, Calcium and Voltage Alternans on Sarcomere Length}

Simulations with our strongly coupled electromechanical myocyte model showed that, alternans magnitude changed as SL decreased from 2.4 to $1.65 \mu \mathrm{m}$. An example of the dependence of the three types of alternans magnitude on SL functions for pacing at a CL of 600 ms $(100 \mathrm{bpm})$ is shown in Figure 4A-C, solid line. CA-ALTM increased for SL>2.05 $\mu \mathrm{m}$ (in Figure 4B) due to diminished myofilament feedback during the even beat only, which occurred as a result of a progressive increase in the fraction of single-overlap thin filament apposing the thick filament as SL increased. Since this portion of the thin filament has a higher binding affinity to calcium, a larger fraction of it caused greater calcium-Troponin $\mathrm{C}$ binding for a given $[\mathrm{Ca}]_{\mathrm{i}}$. This progressively lowered the $[\mathrm{Ca}]_{\mathrm{i}}$ threshold at which Troponin $\mathrm{C}$ became saturated, preventing additional free calcium from binding to Troponin $\mathrm{C}$, despite the peak magnitude of the $[\mathrm{Ca}]_{i}$ transient being greater than the $[\mathrm{Ca}]_{i}$ threshold for saturation. This saturation only occurred during the even beat due to its larger $[\mathrm{Ca}]_{\mathrm{i}}$ magnitude. Since $[\mathrm{Ca}]_{\text {Troponin }}$ is a function of the amount of calcium bound to Troponin $\mathrm{C}$, myofilament feedback was increasingly diminished at progressively larger SLs during the even beat relative to the odd, thus steadily reducing the 
magnitude of $[\mathrm{Ca}]_{\mathrm{i}}$ during the even beat (according to Equation 1). This resulted in progressively larger CA-ALTM, according to Equation 2, at increasingly greater SLs for SL>2.05 $\mu \mathrm{m}$. The saturation of Troponin $\mathrm{C}$ during the even beat also prevented enhanced thin filament activation, which, as described in Section 3.2., resulted in progressively diminished FORCE-ALTM, as shown for SL increasing above $2.05 \mu \mathrm{m}$ in Figure 4A. APV-ALTM decreased for SL>2.05 $\mu \mathrm{m}$, despite increased CA-ALTM, due to increasingly diminished $[\mathrm{Ca}]_{\text {Troponin }}$ during the even beat (as described above), which caused the $[\mathrm{Ca}]_{\mathrm{i}}$ transient during the even beat to have a notched appearance similar to Figure $2 \mathrm{~A}$ (red lines). As SL increased, the $[\mathrm{Ca}]_{i}$ magnitude prior to the $[\mathrm{Ca}]_{\mathrm{i}}$ notch became increasingly large (due to reduced $[\mathrm{Ca}]_{\text {Troponin }}$ ), causing CA-ALTM to increase in accordance with Equation 1 . However, the $[\mathrm{Ca}]_{i}$ transient quickly decreased from the peak value preceding the notch in $[\mathrm{Ca}]_{i}$ to an increasingly smaller value as SL increased, thus shortening Phase II of the action potential and reducing its magnitude during the even beat and inducing smaller APV-ALTM. CA-ALTM also increased for SL<2.05 $\mu \mathrm{m}$. As SL became progressively smaller, the fraction of single-overlap thin filament that was apposed to thick filament decreased, causing reduced calcium-Troponin $\mathrm{C}$ binding for a given $[\mathrm{Ca}]_{\mathrm{i}}$. This diminished thin filament activation and decreased the number of RUs that transitioned from $\mathrm{N}_{\mathrm{XB}}$ to $\mathrm{P}_{\mathrm{XB}}$, thus reducing the number of RUs that transitioned to strongly-bound $\mathrm{XB}$ states. Since $[\mathrm{Ca}]_{\text {Troponin }}$ is a function of the amount of calcium bound to Troponin $\mathrm{C}$ and of the number of RUs in the strongly-bound XB states, myofilament feedback was progressively diminished during the even relative to the odd beat as SL decreased, thus increasing the magnitude of $[\mathrm{Ca}]_{\mathrm{i}}$ more during the even beat. This resulted in progressively larger CA-ALTM as SL decreased for SL $<2.05 \mu \mathrm{m}$. FORCE-ALTM and APV-ALTM were large at SL $<2.05 \mu \mathrm{m}$ due to large CAALM. The trends for CA-ALTM and APV-ALT as functions of SL were different at slow and fast pacing rates (Figure 4E-F), while the dependence of FORCE-ALTM held true at all CLs (Figure 4D).

Eliminating myofilament feedback expanded the range of FORCE-ALTM (Figure 4A, dashed line) without altering the shape of its dependence on SL. As expected, the removal of myofilament feedback rendered CA-ALTM and APV-ALTM insensitive to SL changes (Figure 4B-C, dashed line). FORCE-ALTM was larger in the weakly coupled model at SL $<2.0 \mu \mathrm{m}$ due to larger CA-ALTM; it was smaller at SL>2.0 $\mu \mathrm{m}$ due to enhanced saturation of Troponin C caused by the larger $[\mathrm{Ca}]_{\mathrm{i}}$ magnitudes shown to occur in the weakly coupled model (Figure 2I). This resulted in smaller peak active force generation during the even beat and thus diminished FORCE-ALTM (via Equation 2) in the weakly coupled model.

\subsection{Effect of Heart Failure Induced- Remodeling of Mechanical Parameters on Force, Calcium and Voltage Alternans}

Incorporating heart failure induced-remodeling of both electrical and mechanical parameters in simulations with our strongly coupled electromechanical myocyte model demonstrated that of the mechanical parameters involved in thin filament activation and XB cycling, only remodeling in perm ${ }_{50}$ (half activation constant for shift of a thin filament RU from $\mathrm{N}_{\mathrm{XB}}$ to $\mathrm{P}_{\mathrm{XB}}$ ), $\mathrm{k}_{\mathrm{offH}}$ (rate constant for $\mathrm{Ca}^{2+}$ unbinding from the high affinity binding site of Troponin $\mathrm{C}$ ), and $\mathrm{k}_{\text {on }}$ (rate constant for $\mathrm{Ca}^{2+}$ binding to Troponin $\mathrm{C}$ ) caused appreciable alterations in FORCE-ALTM, CA-ALTM, and APV-ALTM. Of these three, perm 50 was the most important because changes to it had the most profound effects on FORCE-ALTM, CA-

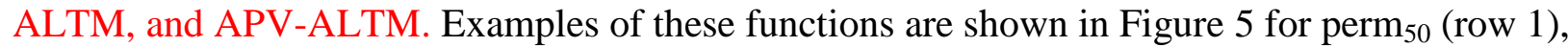
$\mathrm{k}_{\text {offH }}$ (row 2), and $\mathrm{k}_{\text {on }}$ (row 3) for pacing at a CL of $600 \mathrm{~ms}$ and SL of $2.1 \mu \mathrm{m}$, where each 
remodeled parameter is displayed as a percent of its normal value. By definition, increasing perm $_{50}$ diminishes thin filament activation. As perm 50 was progressively increased above $102 \%$, thin filament activation was increasingly reduced, which steadily increased CA-ALTM, FORCEALTM and APV-ALTM, via the mechanisms described in Section 3.3 for SL $<2.05 \mu \mathrm{m}$. As perm $_{50}$ was decreased below $102 \%$, thin filament activation was increasingly enhanced, which increased the transition rate of $\mathrm{N}_{\mathrm{XB}}$ to $\mathrm{P}_{\mathrm{XB}}$ and decreased the reverse rate, causing more RUs to transition to $\mathrm{P}_{\mathrm{XB}}$. A greater number of RUs in the $\mathrm{P}_{\mathrm{XB}}$ state induced additional RUs to transition to the strongly-bound XB states, increasing the fraction of total RUs with strongly-bound XBs. Therefore, achieving the maximum fraction of RUs in the $\mathrm{XB}_{\text {PreR }}$ and $\mathrm{XB}_{\text {PostR }}$ states could be attained with increasingly less activating calcium as perm ${ }_{50}$ decreased. Since $[\mathrm{Ca}]_{\text {Troponin }}$ is a function of the fraction of total RUs in strongly-bound XB states and since during the even beat $[\mathrm{Ca}]_{\mathrm{i}}$ was large enough to attain that maximum fraction, myofilament feedback was progressively diminished during the even relative to the odd beat as perm ${ }_{50}$ decreased, thus increasing the magnitude of $[\mathrm{Ca}]_{\mathrm{i}}$ more during the even beat. This caused progressively larger CA-ALTM. Active force, which is also a function of the fraction of total RUs in strongly-bound XB states, was progressively diminished during the even verses the odd beat (similar to $[\mathrm{Ca}]_{\text {Troponin }}$ ), which resulted in progressively smaller FORCE-ALTM, despite enhanced CA-ALTM, as perm 50 decreased. APV-ALTM was enhanced due to larger CA-ALTM. By definition, a decrease in $\mathrm{k}_{\mathrm{offH}}$ or an increase in $\mathrm{k}_{\text {on }}$ increases the binding affinity of Troponin $\mathrm{C}$ to calcium. As $\mathrm{k}_{\text {offH }}$ was progressively decreased below $103 \%$ and $\mathrm{k}_{\text {on }}$ increased above $92 \%$, binding affinity was increased (thus enhancing calcium-Troponin $\mathrm{C}$ binding for a given $[\mathrm{Ca}]_{\mathrm{i}}$ ), which progressively enhanced CA-ALTM and diminished FORCE-ALTM and APV-ALTM, in the same manner as described in Section 3.3. for $\mathrm{SL}>2.05 \mu \mathrm{m}$. $\mathrm{k}_{\mathrm{offH}}>103 \%$ and $\mathrm{k}_{\mathrm{on}}<92 \%$ decreased the binding affinity of Troponin (thus diminishing thin filament activation), which progressively increased CA-ALTM, FORCE-ALTM and APV-ALTM as described in Section 3.3 for SL<2.05 $\mu \mathrm{m}$. Removing myofilament feedback decreased FORCE-ALTM for nearly all values of perm ${ }_{50}, \mathrm{k}_{\text {offH }}$, and $\mathrm{k}_{\text {on }}$ (Figure 5, column 1, dashed line), and as expected, rendered CA-ALTM and APVALTM insensitive to remodeling of those mechanical parameters. FORCE-ALTM was diminished due to enhanced saturation of Troponin $\mathrm{C}$ caused by the larger $[\mathrm{Ca}]_{\mathrm{i}}$ magnitudes occurring in the weakly coupled model (Figure 2I) in the same manner as described for SL>2.0 $\mu \mathrm{m}$ in Section 3.3.

Finally, simulations were run incorporating only mechanical remodeling (no electrical remodeling). For all CLs and SLs studied, there was no FORCE-ALT, demonstrating that abnormal intracellular calcium handling and thus CA-ALT was necessary for the generation of FORCE-ALT.

\section{Discussion}

The present study examines the cellular mechanisms underlying the formation of pressure alternans (FORCE-ALT) in the presence of MTWA (APV-ALT), which have been shown to be predictors of worsening heart failure and lethal ventricular arrhythmias, respectively. The goals of this study were to uncover the mechanisms linking APV-ALT and FORCE-ALT in failing human myocytes and to investigate how the link between those alternans was affected by pacing rate and various physiological conditions. Using a strongly coupled human electromechanical myocyte model, we showed that CA-ALT, induced by decreased $\mathrm{I}_{\mathrm{up}}$, was the link between APVALT and FORCE-ALT and that FORCE-ALTM was largest at clinically-relevant slow to 

ALTM, CA-ALTM and APV-ALTM were altered by heart failure induced-remodeling of mechanical parameters and by sarcomere length; this was due to the presence of myofilament feedback. Together these findings link FORCE-ALT to APV-ALT and suggest that pressure alternans is directly linked to MTWA via calcium dysregulation and may be a better predictor of the propensity for ventricular arrhythmias at clinically relevant pacing rates $(<110 \mathrm{bpm})$.

\subsection{Calcium Alternans Link Action Potential Voltage Alternans to Force Alternans}

MTWA is caused by CA-ALT predominantly as a result of decreased sarcoplasmic reticulum calcium uptake current $\left(\mathrm{I}_{\mathrm{up}}\right)$ in heart failure patients at near resting heart rates (Bayer et al., 2010; Narayan et al., 2008). In addition, MTWA and pressure alternans have been shown to occur simultaneously in patients at such pacing rates (Selvaraj et al., 2011). Furthermore, patients with pressure alternans have significantly lower amounts of sarcoplasmic reticulum $\mathrm{Ca}^{2+}$-ATPase (SERCA) mRNA than patients without (Hirashiki et al., 2010; Hirashiki et al., 2006). Finally, FORCE-ALT, the cellular manifestation of pressure alternans, has been found to be regulated by calcium dysregulation in animal experiments with cardiac muscle preparations (Kihara and Morgan, 1991; Kotsanas et al., 1996; Lab and Lee, 1990; Orchard et al., 1991) and perfused hearts (Brooks et al., 1994; Lee et al., 1988), paced at fast rates. Taken together, the results from these previous studies have suggested that CA-ALT, due to reduced $\mathrm{I}_{\text {up }}$, is a likely candidate to underlie FORCE-ALT in human heart failure. Our results presented here provide the proof that CA-ALT, via reduced $\mathrm{I}_{\text {up }}$, drove the formation of FORCE-ALT at clinically relevant pacing rates.

\subsection{Force Alternans Are Large at Slow Pacing Rates and May Be Undetectable at Faster Pacing Rates}

Studies have shown that the mean heart rate onset at which pressure alternans were first detected in pacing studies was $606 \mathrm{~ms}$ (99 bpm) (Hirashiki et al., 2006), and 517 to $571 \mathrm{~ms}$ (116 bpm - 105 bpm) (Selvaraj et al., 2011). In addition, a study conducted during normal sinus rhythm found that patients with pressure alternans had significantly slower heart rates than those without (81.0 bpm vs $93.1 \mathrm{bpm}$ ) (Kim et al., 2014). That same study also showed that patients with both MTWA and pressure alternans had slower heart rates than those with only MTWA (81.0 bpm vs $92 \mathrm{bpm}$, not statistically significant), suggesting that patients with only MTWA may have had small yet undetectable pressure alternans due to the alternans magnitude being markedly reduced at faster heart rates. One study further supported this hypothesis by showing that the amplitude of pressure alternans declined at increasingly faster pacing rates for four patients, three of whom lost pressure alternans when pacing rates exceeded 120, 130 and 140 bpm (500, 462, $400 \mathrm{~ms}$ ) respectively (Kashimura et al., 2013). The present study provided support of this finding, since we demonstrated that FORCE-ALTM was greatest at slower pacing rates $(>109 \mathrm{bpm})$ and declined significantly at faster pacing rates $(<109 \mathrm{bpm})$. However, the outcome of one study contradicted these findings and reported that the magnitude of pressure alternans increased from $600 \mathrm{~ms}$ to $500 \mathrm{~ms}$ (Selvaraj et al., 2011). This conflicting evidence might have arisen from the method of calculating pressure alternans magnitude in that study, which differed from ours (spectral analysis versus measuring the amplitude change between the odd and even beats). To date, few patient studies have investigated the effects of pacing rate on the detection and magnitude of pressure alternans. However, as we have shown, pacing rate affects FORCE-ALTM and could explain why some patients with MTWA do not have 

studies of pressure alternans in heart failure patients are needed to investigate this phenomenon in greater detail.

\subsection{Implications of Heart Failure-Induced Mechanical Remodeling for Alternans Severity}

Studies have shown that thin filament activation can be altered in human heart failure. Specifically, decreased phosphorylation of cardiac Troponin I has been shown to be significantly decreased in human heart failure (Messer et al., 2007; Zaremba et al., 2007), resulting in reduced sliding speed and an increased $\mathrm{Ca} 2+-$ sensitivity. Although this change in thin filament activation has been observed in human heart failure, to date no studies have investigated whether it is reduced in patients with pressure alternans or MTWA. Here we demonstrated that heart failureinduced mechanical remodeling of parameters that modify thin filament activation can both exacerbate and diminish FORCE-ALT, CA-ALT, and APV-ALT. These results could explain the results of some studies which have revealed two different populations of patients with alternans: those with both MTWA and pressure alternans and those with only MTWA (Kim et al., 2014; Kodama et al., 2001; Selvaraj et al., 2011). The patient population with both types of alternans could have calcium handling abnormalities and reduced thin filament activation, which would (as our results suggest) result in larger and thus more easily detectable pressure alternans. The patients in which only MTWA were detectable may either have less severe reductions in thin filament activation or no abnormalities at all, and thus have smaller and undetectable pressure alternans. Furthermore, one study has shown that the magnitude of MTWA in patients with both MTWA and pressure alternans is larger than in patients with only MTWA (Kim et al., 2014), suggesting that if those patients had reduced thin filament activation as we speculated, then that would enhance the magnitude of MTWA, in agreement with our results (Figure 5).

\section{Conclusions}

APV-ALT and FORCE-ALT are linked via CA-ALT, resulting from reductions in sarcoplasmic reticulum calcium uptake current, in a strongly coupled electromechnical model of the failing human myocyte. Our results demonstrate that the magnitude of FORCE-ALT is largest at clinically relevant pacing rates $(<110 \mathrm{bpm})$, where APV-ALT was smallest. The magnitudes of FORCE-ALTM, CA-ALTM and APV-ALTM were dependent on pacing rate. Due to myofilament feedback, the magnitude of the alternans was also dependent on sarcomere length, and on the level of heart failure induced-remodeling of mechanical parameters involved in thin filament regulation. These findings provide important insight into the cellular mechanisms underlying pressure alternans at clinically relevant pacing rates $(<110 \mathrm{bpm})$ and may aid in investigating whether pressure alternans is an improved and reliable predictor of propensity for ventricular arrhythmias in human heart failure.

\section{Acknowledgements}

The authors thank Dr. Jason Bayer, University of Bordeaux, and Robert Blake, Johns Hopkins University, for their valuable assistance in this study. This research was supported by National Institute of Health grants numbers R01 HL103428 and DP1 HL123271, and National Science 
Foundation grant number IOS-1124804 to Dr. Trayanova and by the David C. Gakenheimer Fellowship to Melanie Zile.

\section{References}

Ambardekar, A.V., Walker, J.S., Walker, L.A., Cleveland, J.C., Jr., Lowes, B.D. and Buttrick, P.M., 2011. Incomplete recovery of myocyte contractile function despite improvement of myocardial architecture with left ventricular assist device support, Circ Heart Fail. 4, 425-32.

Bardy, G.H., Lee, K.L., Mark, D.B., Poole, J.E., Packer, D.L., Boineau, R., Domanski, M., Troutman, C., Anderson, J., Johnson, G., McNulty, S.E., Clapp-Channing, N., DavidsonRay, L.D., Fraulo, E.S., Fishbein, D.P., Luceri, R.M. and Ip, J.H., 2005. Amiodarone or an implantable cardioverter-defibrillator for congestive heart failure, N Engl J Med. 352, 225-37.

Bayer, J.D., Narayan, S.M., Lalani, G.G. and Trayanova, N.A., 2010. Rate-dependent action potential alternans in human heart failure implicates abnormal intracellular calcium handling, Heart Rhythm. 7, 1093-101.

Belin, R.J., Sumandea, M.P., Allen, E.J., Schoenfelt, K., Wang, H., Solaro, R.J. and de Tombe, P.P., 2007. Augmented protein kinase C-alpha-induced myofilament protein phosphorylation contributes to myofilament dysfunction in experimental congestive heart failure, Circ Res. 101, 195-204.

Belin, R.J., Sumandea, M.P., Kobayashi, T., Walker, L.A., Rundell, V.L., Urboniene, D., Yuzhakova, M., Ruch, S.H., Geenen, D.L., Solaro, R.J. and de Tombe, P.P., 2006. Left ventricular myofilament dysfunction in rat experimental hypertrophy and congestive heart failure, Am J Physiol Heart Circ Physiol. 291, H2344-53.

Berger, R.D., Kasper, E.K., Baughman, K.L., Marban, E., Calkins, H. and Tomaselli, G.F., 1997. Beat-to-beat QT interval variability: novel evidence for repolarization lability in ischemic and nonischemic dilated cardiomyopathy, Circulation. 96, 1557-65.

Bloomfield, D.M., Bigger, J.T., Steinman, R.C., Namerow, P.B., Parides, M.K., Curtis, A.B., Kaufman, E.S., Davidenko, J.M., Shinn, T.S. and Fontaine, J.M., 2006. Microvolt Twave alternans and the risk of death or sustained ventricular arrhythmias in patients with left ventricular dysfunction, J Am Coll Cardiol. 47, 456-63.

Brooks, W.W., Bing, O.H., Litwin, S.E., Conrad, C.H. and Morgan, J.P., 1994. Effects of treppe and calcium on intracellular calcium and function in the failing heart from the spontaneously hypertensive rat, Hypertension. 24, 347-56.

Chen, X., Hu, Y., Fetics, B.J., Berger, R.D. and Trayanova, N.A., 2011. Unstable QT interval dynamics precedes ventricular tachycardia onset in patients with acute myocardial infarction: a novel approach to detect instability in QT interval dynamics from clinical ECG, Circ Arrhythm Electrophysiol. 4, 858-66.

Chen, X., Tereshchenko, L.G., Berger, R.D. and Trayanova, N.A., 2013. Arrhythmia risk stratification based on QT interval instability: an intracardiac electrocardiogram study, Heart Rhythm. 10, 875-80.

Chen, X. and Trayanova, N.A., 2012. A novel methodology for assessing the bounded-input bounded-output instability in QT interval dynamics: application to clinical ECG with ventricular tachycardia, IEEE Trans Biomed Eng. 59, 2111-7. 
Couderc, J.P., Zareba, W., McNitt, S., Maison-Blanche, P. and Moss, A.J., 2007. Repolarization variability in the risk stratification of MADIT II patients, Europace. 9, 717-23.

Coulton, A.T. and Stelzer, J.E., 2012. Cardiac myosin binding protein C and its phosphorylation regulate multiple steps in the cross-bridge cycle of muscle contraction, Biochemistry. 51, 3292-301.

Cutler, M.J. and Rosenbaum, D.S., 2009. Risk stratification for sudden cardiac death: is there a clinical role for T wave alternans?, Heart Rhythm. 6, S56-61.

Das, M.K., Khan, B., Jacob, S., Kumar, A. and Mahenthiran, J., 2006. Significance of a fragmented QRS complex versus a Q wave in patients with coronary artery disease, Circulation. 113, 2495-501.

de Oliveira, B.L., Rocha, B.M., Barra, L.P., Toledo, E.M., Sundnes, J. and Weber dos Santos, R., 2013. Effects of deformation on transmural dispersion of repolarization using in silico models of human left ventricular wedge, Int J Numer Method Biomed Eng. 29, 1323-37.

de Waard, M.C., van der Velden, J., Bito, V., Ozdemir, S., Biesmans, L., Boontje, N.M., Dekkers, D.H., Schoonderwoerd, K., Schuurbiers, H.C., de Crom, R., Stienen, G.J., Sipido, K.R., Lamers, J.M. and Duncker, D.J., 2007. Early exercise training normalizes myofilament function and attenuates left ventricular pump dysfunction in mice with a large myocardial infarction, Circ Res. 100, 1079-88.

El-Armouche, A., Pohlmann, L., Schlossarek, S., Starbatty, J., Yeh, Y.H., Nattel, S., Dobrev, D., Eschenhagen, T. and Carrier, L., 2007. Decreased phosphorylation levels of cardiac myosin-binding protein- $\mathrm{C}$ in human and experimental heart failure, $\mathrm{J}$ Mol Cell Cardiol. 43, 223-9.

Flashman, E., Redwood, C., Moolman-Smook, J. and Watkins, H., 2004. Cardiac myosin binding protein C: its role in physiology and disease, Circ Res. 94, 1279-89.

Goldberger, J.J., Buxton, A.E., Cain, M., Costantini, O., Exner, D.V., Knight, B.P., Lloyd-Jones, D., Kadish, A.H., Lee, B., Moss, A., Myerburg, R., Olgin, J., Passman, R., Rosenbaum, D., Stevenson, W., Zareba, W. and Zipes, D.P., 2011. Risk stratification for arrhythmic sudden cardiac death: identifying the roadblocks, Circulation. 123, 2423-30.

Gordon, A.M., Huxley, A.F. and Julian, F.J., 1966. The variation in isometric tension with sarcomere length in vertebrate muscle fibres, J Physiol. 184, 170-92.

Hasenfuss, G., Reinecke, H., Studer, R., Meyer, M., Pieske, B., Holtz, J., Holubarsch, C., Posival, H., Just, H. and Drexler, H., 1994. Relation between myocardial function and expression of sarcoplasmic reticulum $\mathrm{Ca}(2+)$-ATPase in failing and nonfailing human myocardium, Circ Res. 75, 434-42.

Hirashiki, A., Izawa, H., Cheng, X.W., Unno, K., Ohshima, S. and Murohara, T., 2010. Dobutamine-induced mechanical alternans is a marker of poor prognosis in idiopathic dilated cardiomyopathy, Clin Exp Pharmacol Physiol. 37, 1004-9.

Hirashiki, A., Izawa, H., Somura, F., Obata, K., Kato, T., Nishizawa, T., Yamada, A., Asano, H., Ohshima, S., Noda, A., Iino, S., Nagata, K., Okumura, K., Murohara, T. and Yokota, M., 2006. Prognostic value of pacing-induced mechanical alternans in patients with mild-tomoderate idiopathic dilated cardiomyopathy in sinus rhythm, J Am Coll Cardiol. 47, 1382-9.

Hohnloser, S.H., Ikeda, T. and Cohen, R.J., 2009. Evidence regarding clinical use of microvolt T-wave alternans, Heart Rhythm. 6, S36-44.

Ito, M., Kodama, M., Kashimura, T., Obata, H., Mitsuma, W., Hirono, S., Tomita, M., Ohno, Y., Tanabe, N. and Aizawa, Y., 2012. Comparison of patients with pulmonary arterial 
hypertension with versus without right-sided mechanical alternans, Am J Cardiol. 109, 428-31.

Ji, Y.C., Gray, R.A. and Fenton, F.H., 2015. Implementation of Contraction to Electrophysiological Ventricular Myocyte Models, and Their Quantitative Characterization via Post-Extrasystolic Potentiation, PLoS One. 10, e0135699.

Kashimura, T., Kodama, M., Tanaka, K., Sonoda, K., Watanabe, S., Ohno, Y., Tomita, M., Obata, H., Mitsuma, W., Ito, M., Hirono, S., Hanawa, H. and Aizawa, Y., 2013. Mechanical alternans in human idiopathic dilated cardiomyopathy is caused with impaired force-frequency relationship and enhanced poststimulation potentiation, Heart Vessels. 28, 336-44.

Kashimura, T., Kodama, M., Watanabe, T., Tanaka, K., Hayashi, Y., Ohno, Y., Obata, H., Ito, M., Hirono, S., Hanawa, H. and Minamino, T., 2014. Relative refractoriness of left ventricular contraction underlies human tachycardia-induced mechanical and electrical alternans, Pacing Clin Electrophysiol. 37, 197-206.

Kihara, Y. and Morgan, J.P., 1991. Abnormal Cai2+ handling is the primary cause of mechanical alternans: study in ferret ventricular muscles, Am J Physiol. 261, H1746-55.

Kim, R., Cingolani, O., Wittstein, I., McLean, R., Han, L., Cheng, K., Robinson, E., Brinker, J., Schulman, S.S., Berger, R.D., Henrikson, C.A. and Tereshchenko, L.G., 2014. Mechanical alternans is associated with mortality in acute hospitalized heart failure: prospective mechanical alternans study (MAS), Circ Arrhythm Electrophysiol. 7, 259-66.

Kockskamper, J. and Blatter, L.A., 2002. Subcellular Ca2+ alternans represents a novel mechanism for the generation of arrhythmogenic $\mathrm{Ca} 2+$ waves in cat atrial myocytes, $\mathrm{J}$ Physiol. 545, 65-79.

Kodama, M., Kato, K., Hirono, S., Okura, Y., Hanawa, H., Ito, M., Fuse, K., Shiono, T., Watanabe, K. and Aizawa, Y., 2001. Mechanical alternans in patients with chronic heart failure, J Card Fail. 7, 138-45.

Kotsanas, G., Holroyd, S.M., Young, R. and Gibbs, C.L., 1996. Mechanisms contributing to pulsus alternans in pressure-overload cardiac hypertrophy, Am J Physiol. 271, H2490500 .

Kuchar, D.L., Thorburn, C.W. and Sammel, N.L., 1987. Prediction of serious arrhythmic events after myocardial infarction: signal-averaged electrocardiogram, Holter monitoring and radionuclide ventriculography, J Am Coll Cardiol. 9, 531-8.

Lab, M.J. and Lee, J.A., 1990. Changes in intracellular calcium during mechanical alternans in isolated ferret ventricular muscle, Circ Res. 66, 585-95.

Lamberts, R.R., Hamdani, N., Soekhoe, T.W., Boontje, N.M., Zaremba, R., Walker, L.A., de Tombe, P.P., van der Velden, J. and Stienen, G.J., 2007. Frequency-dependent myofilament $\mathrm{Ca} 2+$ desensitization in failing rat myocardium, J Physiol. 582, 695-709.

Lee, H.C., Mohabir, R., Smith, N., Franz, M.R. and Clusin, W.T., 1988. Effect of ischemia on calcium-dependent fluorescence transients in rabbit hearts containing indo 1. Correlation with monophasic action potentials and contraction, Circulation. 78, 1047-59.

Levine, R.J., Kensler, R.W., Yang, Z., Stull, J.T. and Sweeney, H.L., 1996. Myosin light chain phosphorylation affects the structure of rabbit skeletal muscle thick filaments, Biophys $\mathrm{J}$. 71, 898-907.

Lloyd-Jones, D., Adams, R., Carnethon, M., De Simone, G., Ferguson, T.B., Flegal, K., Ford, E., Furie, K., Go, A., Greenlund, K., Haase, N., Hailpern, S., Ho, M., Howard, V., Kissela, B., Kittner, S., Lackland, D., Lisabeth, L., Marelli, A., McDermott, M., Meigs, J., 

P., Stafford, R., Steinberger, J., Thom, T., Wasserthiel-Smoller, S., Wong, N., WylieRosett, J. and Hong, Y., 2009. Heart disease and stroke statistics--2009 update: a report from the American Heart Association Statistics Committee and Stroke Statistics Subcommittee, Circulation. 119, 480-6.

Messer, A.E., Jacques, A.M. and Marston, S.B., 2007. Troponin phosphorylation and regulatory function in human heart muscle: dephosphorylation of Ser23/24 on troponin I could account for the contractile defect in end-stage heart failure, J Mol Cell Cardiol. 42, 24759.

Moss, R.L. and Fitzsimons, D.P., 2006. Myosin light chain 2 into the mainstream of cardiac development and contractility, Circ Res. 99, 225-7.

Mulieri, L.A., Hasenfuss, G., Leavitt, B., Allen, P.D. and Alpert, N.R., 1992. Altered myocardial force-frequency relation in human heart failure, Circulation. 85, 1743-50.

Narayan, S.M., 2006. T-wave alternans and the susceptibility to ventricular arrhythmias, J Am Coll Cardiol. 47, 269-81.

Narayan, S.M., Bayer, J.D., Lalani, G. and Trayanova, N.A., 2008. Action potential dynamics explain arrhythmic vulnerability in human heart failure: a clinical and modeling study implicating abnormal calcium handling, J Am Coll Cardiol. 52, 1782-92.

Narayan, S.M., Franz, M.R., Lalani, G., Kim, J. and Sastry, A., 2007. T-wave alternans, restitution of human action potential duration, and outcome, J Am Coll Cardiol. 50, 238592.

Olsson, M.C., Patel, J.R., Fitzsimons, D.P., Walker, J.W. and Moss, R.L., 2004. Basal myosin light chain phosphorylation is a determinant of $\mathrm{Ca} 2+$ sensitivity of force and activation dependence of the kinetics of myocardial force development, Am J Physiol Heart Circ Physiol. 287, H2712-8.

Orchard, C.H., McCall, E., Kirby, M.S. and Boyett, M.R., 1991. Mechanical alternans during acidosis in ferret heart muscle, Circ Res. 68, 69-76.

Pastore, J.M., Girouard, S.D., Laurita, K.R., Akar, F.G. and Rosenbaum, D.S., 1999. Mechanism linking T-wave alternans to the genesis of cardiac fibrillation, Circulation. 99, 1385-94.

Patel, J.R., Diffee, G.M., Huang, X.P. and Moss, R.L., 1998. Phosphorylation of myosin regulatory light chain eliminates force-dependent changes in relaxation rates in skeletal muscle, Biophys J. 74, 360-8.

Pieske, B., Sutterlin, M., Schmidt-Schweda, S., Minami, K., Meyer, M., Olschewski, M., Holubarsch, C., Just, H. and Hasenfuss, G., 1996. Diminished post-rest potentiation of contractile force in human dilated cardiomyopathy. Functional evidence for alterations in intracellular Ca2+ handling, J Clin Invest. 98, 764-76.

Qu, Z., Xie, Y., Garfinkel, A. and Weiss, J.N., 2010. T-wave alternans and arrhythmogenesis in cardiac diseases, Front Physiol. 1, 154.

Rice, J.J., Wang, F., Bers, D.M. and de Tombe, P.P., 2008. Approximate model of cooperative activation and crossbridge cycling in cardiac muscle using ordinary differential equations, Biophys J. 95, 2368-90.

Rosenbaum, D.S., Jackson, L.E., Smith, J.M., Garan, H., Ruskin, J.N. and Cohen, R.J., 1994. Electrical alternans and vulnerability to ventricular arrhythmias, N Engl J Med. 330, 23541. 
Schmidt, U., Hajjar, R.J., Kim, C.S., Lebeche, D., Doye, A.A. and Gwathmey, J.K., 1999. Human heart failure: cAMP stimulation of SR $\mathrm{Ca}(2+)$-ATPase activity and phosphorylation level of phospholamban, Am J Physiol. 277, H474-80.

Selvaraj, R.J., Suszko, A., Subramanian, A., Mak, S., Wainstein, R. and Chauhan, V.S., 2011. Microscopic systolic pressure alternans in human cardiomyopathy: noninvasive evaluation of a novel risk marker and correlation with microvolt T-wave alternans, Heart Rhythm. 8, 236-43.

Shkryl, V.M., Maxwell, J.T., Domeier, T.L. and Blatter, L.A., 2012. Refractoriness of sarcoplasmic reticulum $\mathrm{Ca} 2+$ release determines $\mathrm{Ca} 2+$ alternans in atrial myocytes, Am J Physiol Heart Circ Physiol. 302, H2310-20.

ten Tusscher, K.H., Noble, D., Noble, P.J. and Panfilov, A.V., 2004. A model for human ventricular tissue, Am J Physiol Heart Circ Physiol. 286, H1573-89.

ten Tusscher, K.H. and Panfilov, A.V., 2006. Alternans and spiral breakup in a human ventricular tissue model, Am J Physiol Heart Circ Physiol. 291, H1088-100.

Trayanova, N.A. and Rice, J.J., 2011. Cardiac electromechanical models: from cell to organ, Front Physiol. 2, 43.

van der Velden, J., de Jong, J.W., Owen, V.J., Burton, P.B. and Stienen, G.J., 2000. Effect of protein kinase A on calcium sensitivity of force and its sarcomere length dependence in human cardiomyocytes, Cardiovasc Res. 46, 487-95.

van Der Velden, J., Klein, L.J., Zaremba, R., Boontje, N.M., Huybregts, M.A., Stooker, W., Eijsman, L., de Jong, J.W., Visser, C.A., Visser, F.C. and Stienen, G.J., 2001. Effects of calcium, inorganic phosphate, and $\mathrm{pH}$ on isometric force in single skinned cardiomyocytes from donor and failing human hearts, Circulation. 104, 1140-6.

van der Velden, J., Narolska, N.A., Lamberts, R.R., Boontje, N.M., Borbely, A., Zaremba, R., Bronzwaer, J.G., Papp, Z., Jaquet, K., Paulus, W.J. and Stienen, G.J., 2006. Functional effects of protein kinase C-mediated myofilament phosphorylation in human myocardium, Cardiovasc Res. 69, 876-87.

van der Velden, J., Papp, Z., Boontje, N.M., Zaremba, R., de Jong, J.W., Janssen, P.M., Hasenfuss, G. and Stienen, G.J., 2003a. The effect of myosin light chain 2 dephosphorylation on $\mathrm{Ca} 2+$-sensitivity of force is enhanced in failing human hearts, Cardiovasc Res. 57, 505-14.

van der Velden, J., Papp, Z., Zaremba, R., Boontje, N.M., de Jong, J.W., Owen, V.J., Burton, P.B., Goldmann, P., Jaquet, K. and Stienen, G.J., 2003b. Increased Ca2+-sensitivity of the contractile apparatus in end-stage human heart failure results from altered phosphorylation of contractile proteins, Cardiovasc Res. 57, 37-47.

Weiss, J.N., Karma, A., Shiferaw, Y., Chen, P.S., Garfinkel, A. and Qu, Z., 2006. From pulsus to pulseless: the saga of cardiac alternans, Circ Res. 98, 1244-53.

Wolff, M.R., Buck, S.H., Stoker, S.W., Greaser, M.L. and Mentzer, R.M., 1996. Myofibrillar calcium sensitivity of isometric tension is increased in human dilated cardiomyopathies: role of altered beta-adrenergically mediated protein phosphorylation, J Clin Invest. 98, 167-76.

Wolff, M.R., Whitesell, L.F. and Moss, R.L., 1995. Calcium sensitivity of isometric tension is increased in canine experimental heart failure, Circ Res. 76, 781-9.

Xie, W., Santulli, G., Guo, X., Gao, M., Chen, B.X. and Marks, A.R., 2013. Imaging atrial arrhythmic intracellular calcium in intact heart, J Mol Cell Cardiol. 64, 120-3. 
Zaremba, R., Merkus, D., Hamdani, N., Lamers, J.M., Paulus, W.J., Dos Remedios, C., Duncker, D.J., Stienen, G.J. and van der Velden, J., 2007. Quantitative analysis of myofilament protein phosphorylation in small cardiac biopsies, Proteomics Clin Appl. 1, 1285-90. 


\section{Figure Captions}

Figure 1: Strongly Coupled Human Electromechanical Myocyte Model with myofilament feedback via $[\mathrm{Ca}]_{\text {Troponin. }}$. A modified version of the Markov state diagram of the myofilament model from Rice et al, which describes the activation of the thin filament by intracellular calcium binding to Troponin $\mathrm{C}$ as well as thin filament binding to thick filament crossbridges $(\mathrm{XBs})$, is shown. The transition rates $\left(\mathrm{k}_{\mathrm{npT}}\right.$ and $\left.\mathrm{k}_{\mathrm{pnT}}\right)$ between the thin filament states where $\mathrm{XB}$ formation is inhibited $\left(\mathrm{N}_{\mathrm{XB}}\right)$ and where weakly bound $\mathrm{XB}$ formation is possible $\left(\mathrm{P}_{\mathrm{XB}}\right)$ are both functions of perm $50, \mathrm{k}_{\mathrm{on}}, \mathrm{k}_{\mathrm{offH}}$, and $\mathrm{k}_{\mathrm{offL}}$. The rate $\mathrm{k}_{\mathrm{npT}}$ is also dependent on $\mathrm{k}_{\mathrm{n} \_\mathrm{p}}$, and $\mathrm{k}_{\mathrm{pnT}}$ is additionally dependent on $\mathrm{k}_{\mathrm{p} \_n}$. The $\mathrm{XB}_{\text {PreR }}$ and $\mathrm{XB}_{\text {PostR }}$ states represent a thin filament with a strongly bound XB that do not and do, respectively, have rotated myosin heads which induced strain (Rice et al., 2008).

Figure 2: CA-ALT (column 1), APV-ALT (column 2), [Ca $]_{\text {Troponin }}$ (column 3), and FORCEALT (column 4) for simulations incorporating electrical remodeling in the absence of mechanical remodeling for a pacing CL of $650 \mathrm{~ms}$ and for SL=2.1 $\mu \mathrm{m}$. Alternans are plotted over time in row 1 showing that CA-ALT was sufficient to produce APV-ALT, [Ca $]_{\text {Troponin }}$ alternans, and FORCE-ALT. Odd (blue) and even (red) beats from row 1 are superimposed to illustrate that the magnitude of alternans in rows 2 (strongly coupled simulations) and 3 (weakly coupled simulations) were different with and without myofilament feedback.

Figure 3: Dependence of FORCE-ALTM (A), CA-ALTM (B), and APV-ALTM (C) to CL in simulations with electrical remodeling in the absence of mechanical remodeling at $\mathrm{SL}=2.1 \mu \mathrm{m}$ for both the strongly (solid lines) and weakly coupled (dashed lines) models. The purple dashpot line indicates where the data in Figure 4 are taken from $(\mathrm{CL}=600 \mathrm{~ms})$. No alternans occurred for pacing CLs>650 ms for either the strongly or weakly coupled model.

Figure 4: Sensitivity of FORCE-ALTM (A), CA-ALTM (B), and APV-ALTM (C) to SL in simulations with electrical remodeling in the absence of mechanical remodeling at $\mathrm{CL}=600 \mathrm{~ms}$ for both the strongly (solid lines) and weakly (dashed lines) coupled models. Plots of the dependence of FORCE-ALTM (D), CA-ALTM (E), and APV-ALTM (F) on SL are shown for slow and fast pacing rates for the strongly coupled model. The purple dashpot line indicates where the data displayed in Figure 3 are from $(\mathrm{SL}=2.1 \mu \mathrm{m})$.

Figure 5: Dependence of FORCE-ALTM (column 1), CA-ALTM (column 2), and APV-ALTM (column 3) on the level of mechanical remodeling for pacing $\mathrm{CL}=600 \mathrm{~ms}$ and $\mathrm{SL}=2.1 \mu \mathrm{m}$ for the strongly coupled model (solid lines). Dashed line in the FORCE-ALTM refers to the weakly coupled model. Heart-failure remodeling mechanical parameters perm ${ }_{50}$ (row 1), $\mathrm{k}_{\mathrm{offH}}$ (row 2), and $\mathrm{k}_{\mathrm{on}}$ (row 3 ), are displayed as a percent of their normal values. 
Ionic Model

Electrical Remodeling

$[\mathrm{Ca}]_{\text {Total }}=[\mathrm{Ca}]_{\mathrm{i}}$

$+[\mathrm{Ca}]$ Calmodulin

$+[\mathrm{Ca}]$ Troponin

\section{Myofilament Model}

Mechanical Remodeling

$[\mathrm{Ca}]_{\mathrm{i}}$

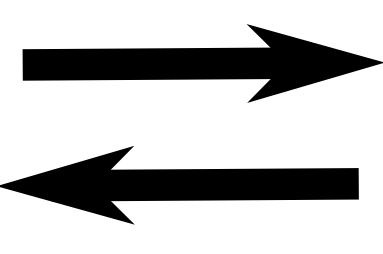

$[\mathrm{Ca}]$ Troponin
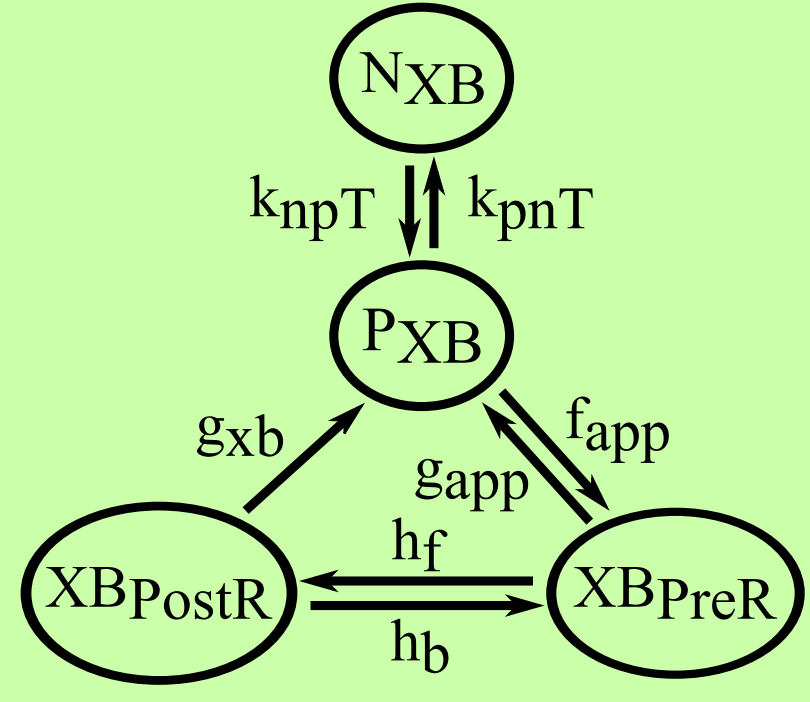
CA-ALT

A.

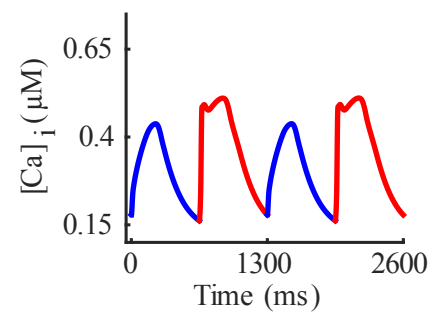

E.

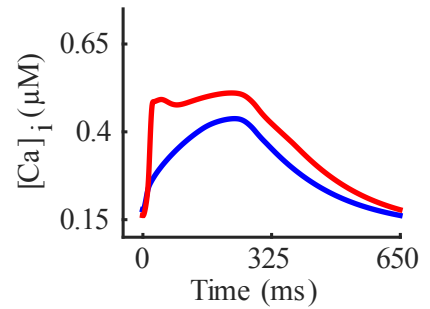

Time (ms)
APV-ALT

B.

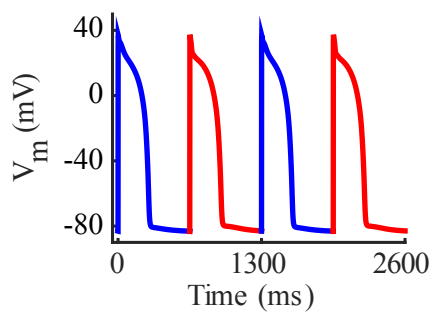

F.

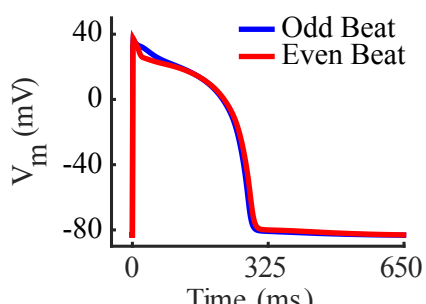

Time (ms)
C.

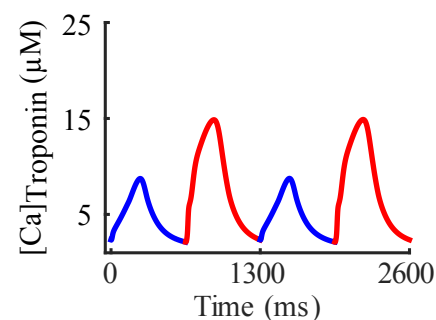

G.

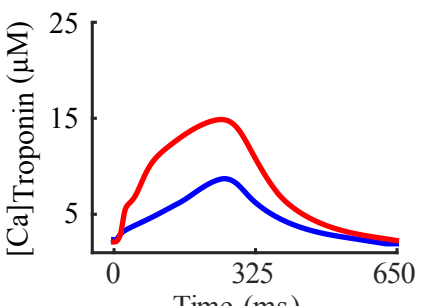

Time (ms)

K.

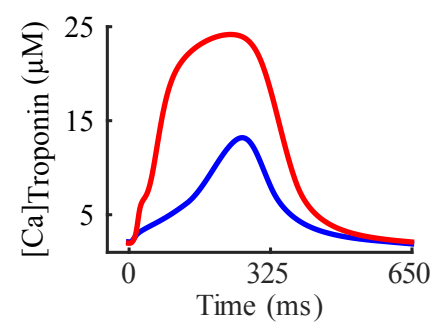

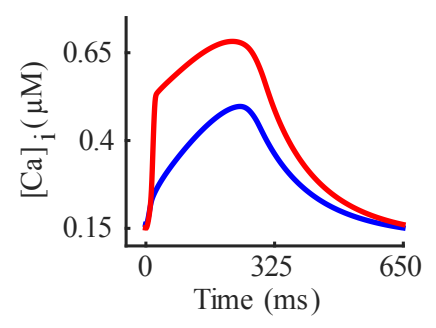

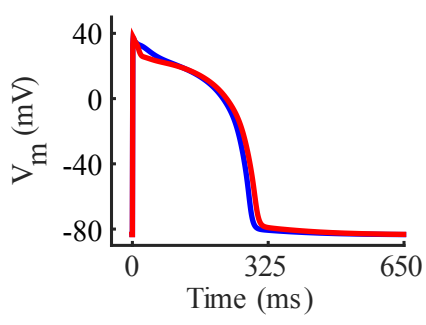

FORCE-ALT

D.

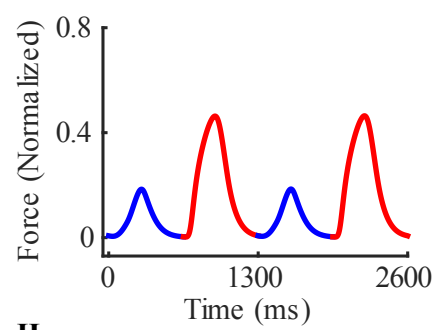

H.

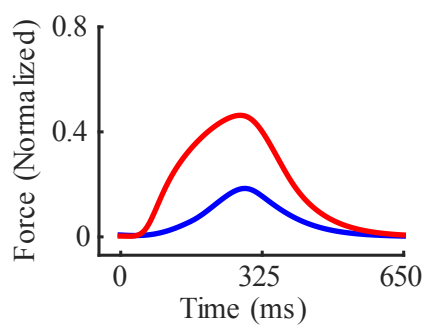

.

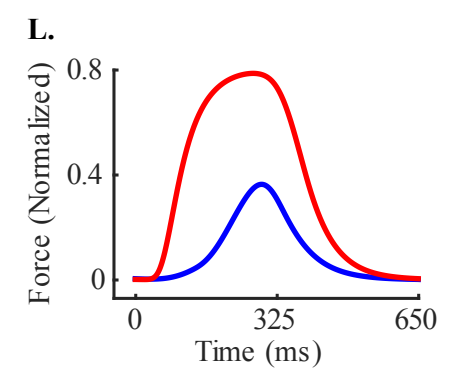

$[\mathbf{C a}]_{\text {Troponin }}$ 
A.

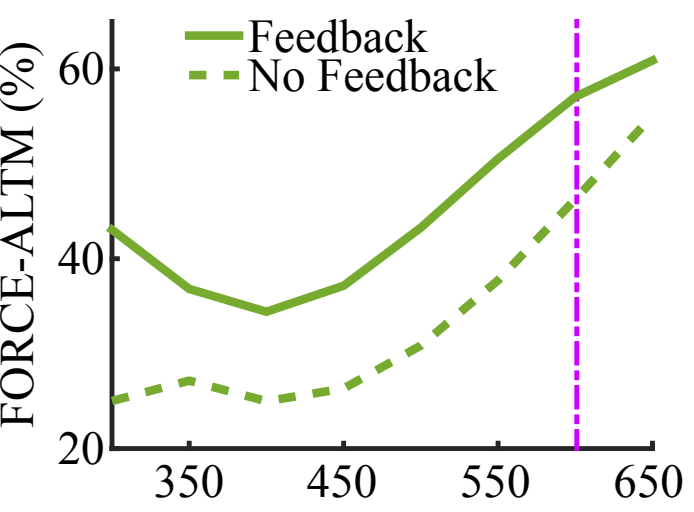

Cycle Length (ms)
B.

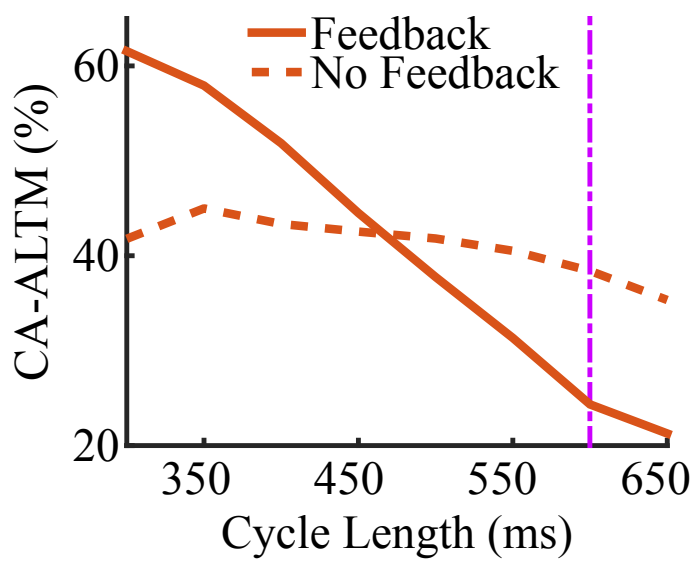

C.

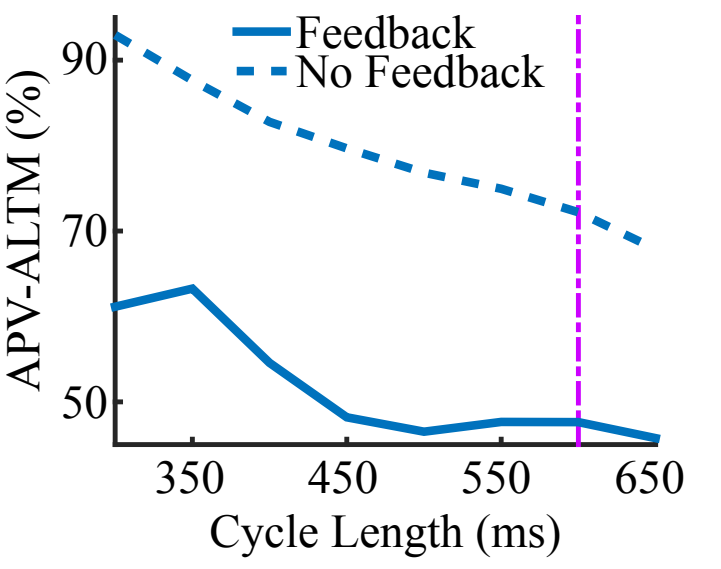


A.

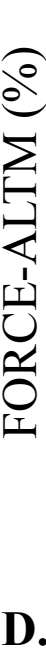

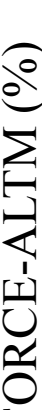

I

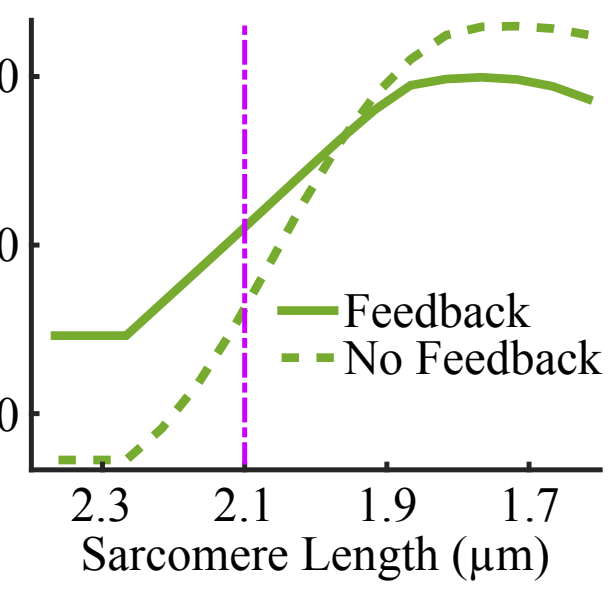

B.

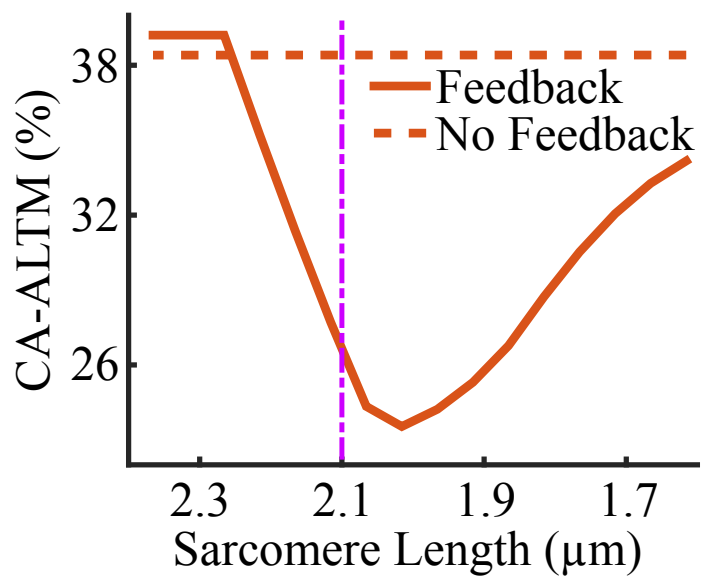

E.

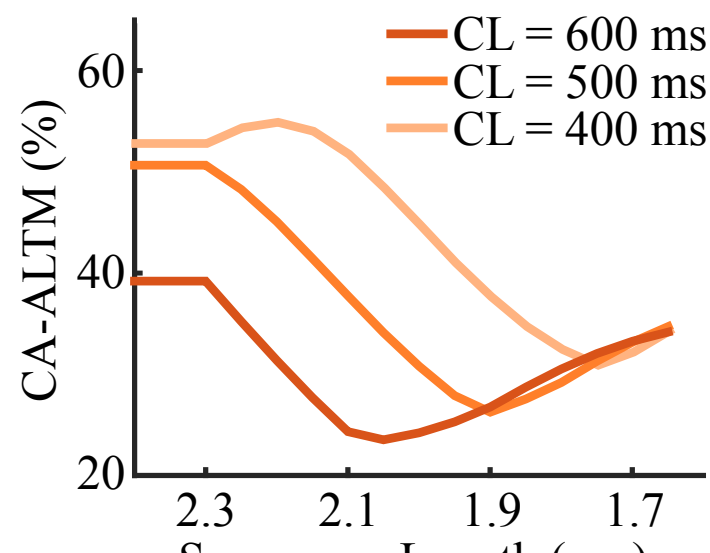

Sarcomere Length $(\mu \mathrm{m})$
C.

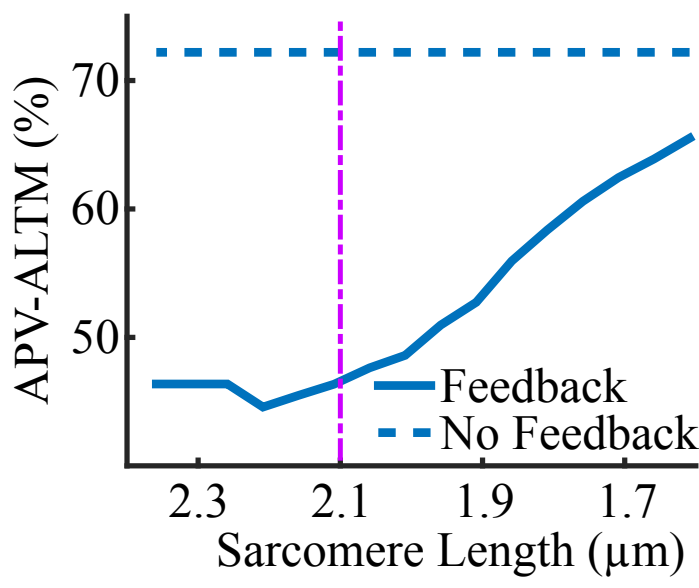

F.

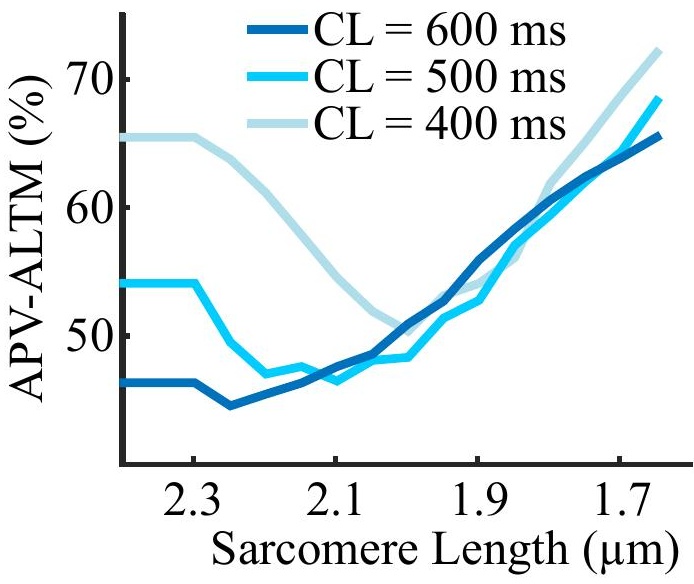



A.
B.
C.
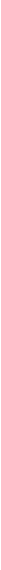

D.

E.

F.
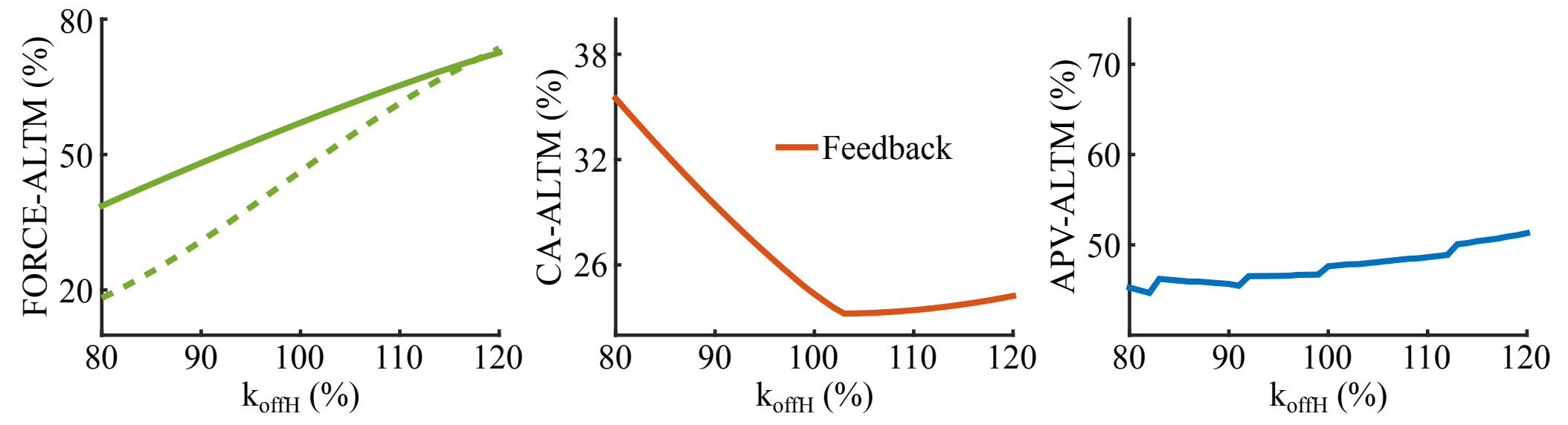

G.

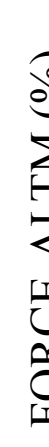

o
H.

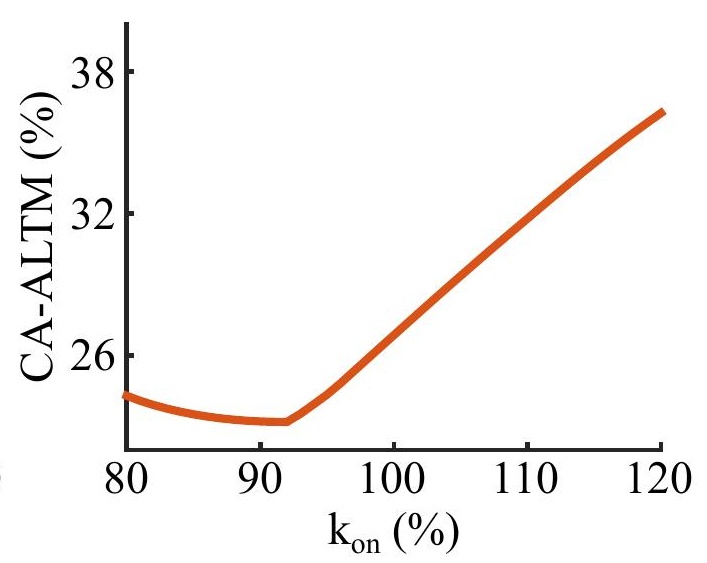

I.

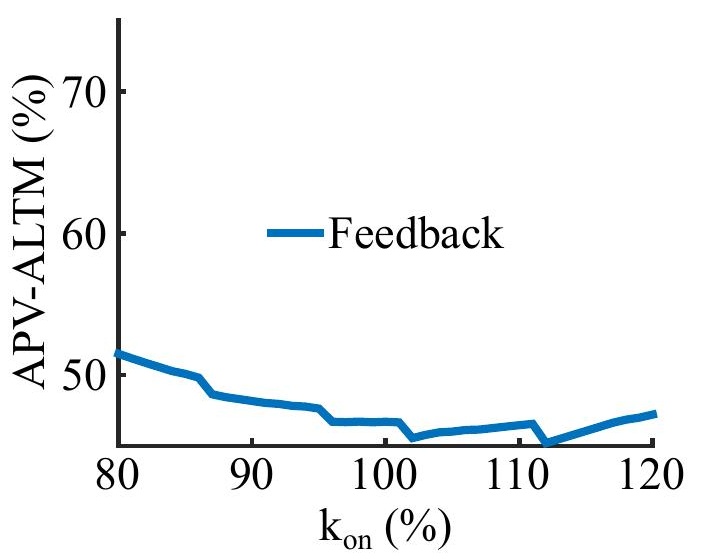




\begin{tabular}{|c|c|c|c|}
\hline Parameter & $\begin{array}{c}\text { Control } \\
\text { Value }(\mathrm{CV})\end{array}$ & $\begin{array}{l}\text { Heart Failure } \\
\text { Value }\end{array}$ & $\begin{array}{l}\text { Effect of HF remodeling } \\
\text { on Alternans }\end{array}$ \\
\hline$I_{u p}$ & $0.006375 \mathrm{mM} / \mathrm{ms}$ & $\mathrm{CV} * 27 \%$ & Required for alternans to occur \\
\hline perm $_{50}$ & 0.5 (unitless) & \multirow{11}{*}{$\begin{array}{c}\text { Range of Values } \\
\text { (Increments of 1\%): } \\
\text { CV*80\% } \\
\text { to } \\
\text { CV*120\% }\end{array}$} & Largest effect on alternans magnitude \\
\hline $\mathrm{k}_{\mathrm{on}}$ & $47.51 / \mu \mathrm{Ms}$ & & Large effect on alternans magnitude \\
\hline $\mathrm{k}_{\mathrm{offH}}$ & $251 / \mathrm{s}$ & & Large effect on alternans magnitude \\
\hline $\mathrm{k}_{\mathrm{offL}}$ & $2501 / \mathrm{s}$ & & \multirow{8}{*}{ Negligible effects on alternans magnitude } \\
\hline $\mathrm{k}_{\mathrm{n}-\mathrm{p}}$ & $0.611 / \mathrm{ms}$ & & \\
\hline $\mathrm{k}_{\mathrm{p} \_\mathrm{n}}$ & $0.0161 / \mathrm{ms}$ & & \\
\hline$f_{\text {app }}$ & $4.81 / \mathrm{ms}$ & & \\
\hline $\mathrm{g}_{\text {app }}$ & $0.0931 / \mathrm{ms}$ & & \\
\hline $\mathrm{h}_{\mathrm{f}}$ & $0.0101 / \mathrm{ms}$ & & \\
\hline $\mathrm{h}_{\mathrm{b}}$ & $0.0351 / \mathrm{ms}$ & & \\
\hline$g_{x b}$ & $0.0301 / \mathrm{ms}$ & & \\
\hline
\end{tabular}

Table 1. Control and Heart Failure values for important model parameters. $I_{u p}$ is from the ten Tusscher et al ionic model (ten Tusscher and Panfilov, 2006). All other parameters are from the Rice et al myofilament model (Rice et al., 2008). 